\title{
Study of assessment of awareness for screening of cervical cancer in women attending gynecology outdoor patient department
}

\author{
Neha S. Lal, Avinashi Kujur*, Pratibha Tiwari
}

Department of Obstetrics and Gynecology, Pt. JNM Medical College, Raipur, Chhattisgarh, India

Received: 28 March 2020

Accepted: 04 April 2020

\section{*Correspondence:}

Dr. Avinashi Kujur,

E-mail: avinashikujur@gmail.com

Copyright: (C) the author(s), publisher and licensee Medip Academy. This is an open-access article distributed under the terms of the Creative Commons Attribution Non-Commercial License, which permits unrestricted non-commercial use, distribution, and reproduction in any medium, provided the original work is properly cited.

\begin{abstract}
Background: Nearly every family in the world is touched by cancer, which is now responsible for almost one in six deaths globally. Aim of this study was to access Indian woman's awareness towards cervical screening methods to promote strategies for increasing its uptake.

Methods: A comprehensive questionnaire based cross-sectional observational survey was conducted in Pt. JNM Medical College and Dr. BRAM hospital, Raipur, Chhattisgarh from September 2018 to July 2019. Participants were selected by sampling between 21 to 59 years of age who have given consent for study.

Results: Out of 1008 participants only 336 (33.3\%) participants were aware about screening of cervical cancer and less than $28 \%$ participants were aware about pap smear, time of investigation, method of pap smear, health centre, association of HPV virus with cervical cancer, availability at vaccination, and with regard to risk factors only $27.9 \%$ women were aware that there is increased risk of cervical cancer due to multiple partners, $17.6 \%$ aware of risk due to increase in number of children's, $11.1 \%$ aware of increase in risk of cervical cancer due to early initiation of sexual activity. Younger women (age 30-35, odds ratio 1.24, 95\% CI 0.78-1.32, p-value 0.05), low socioeconomic status (odds ratio $1.74,95 \%$ CI $0.76-2.12$, p-value 0.01 ), education level ( $\leq$ secondary education odds ratio $1.6495 \% \mathrm{CI}$ 0.85-2.18 p-value 0.000, $\geq$ higher secondary or above education odds ratio $2.3295 \%$ CI 1.21-2.89 p-value 0.001$)$ and age at marriage (odds ratio 2.21, 95\% CI 0.78-2.18, p-value 0.000) all had a significant relationship with the awareness of Pap smear test. Two-third of the females in the study stated that lack of awareness as the major reason for not getting a pap smear while another one- third stated lack of recommendation by health care professionals as major hurdle.

Conclusions: This study found that woman's fear, pain and embarrassment, along with cultural influences, deterred them from undergoing screening.
\end{abstract}

Keywords: Awareness, Cancer cervix, Indian woman, Screening

\section{INTRODUCTION}

Nearly every family in the world is touched by cancer, which is now responsible for almost one in six deaths globally. WHO highlights that cancer no longer needs to be a death sentence, as the capacity exists to reduce its burden and improve the survival and quality of life of people living with the disease. WHO recommends a comprehensive approach to cervical cancer prevention and control. WHO recommended multidisciplinary approach, including components from community education, social mobilization, vaccination, screening, treatment and palliative care. ${ }^{1}$ By strengthening the health system response, we can also ensure early diagnosis, prompt treatment, palliative care and better access to affordable treatment by qualified personnel, thereby saving millions of lives. Detecting cancer early also greatly reduces not only the cost of treatment, but people 
can also continue to work and support their families if they can access effective treatment in time. ${ }^{2}$

Cervical cancer is a largely preventable disease, but worldwide it is one of the leading causes of cancer death in women. Most deaths occur in low to middle income countries. ${ }^{3}$

In India, it is one the leading causes of mortality among women accounting for $23.3 \%$ of all cancer deaths. India accounts for about $20 \%$ of cervical cancer cases reported from the world. ${ }^{4} \mathrm{HPV}$ is the most common infection acquired during sexual relations, usually early in sexual life. A minority of HPV infections persist; in women this may lead to cervical pre malignant lesion, which, if not treated, may progress to cancer 10 to 20 years later.

Cervical cancer can usually be prevented if women are screened regularly with the Pap test. It has helped reduce cervical cancer incidence and mortality rates by $75 \%$. Recently advised approach to diagnosing and treating CIN is to use a 'screen-and-treat' approach in which the treatment decision is based on a screening test, and treatment is provided soon or, ideally, immediately after a positive screening test. ${ }^{5}$

In Indian scenario cervical screening is only performed opportunistically during woman's visits to health facilities. Cervical cancer screening rates in the India are low, and little is known about the perspectives of the Indian women regarding screening.

Thus, present study has been conducted with aim to know about the awareness of cervical cancer screening among Indian women attending in study facility.

\section{METHODS}

A comprehensive questionnaire based cross-sectional observational survey was conducted in Pt. JNM Medical College and Dr. BRAM Hospital, Raipur, Chhattisgarh from September 2018 to July 2019. A total of 1008 women gave consent to participate.

\section{Inclusion criteria}

- Women attending outdoor patient department. Aged between 21 to 59 years willing to participate and who have given consent for study.

\section{Exclusion criteria}

- Women aged below 21 years or above 59 years or not willing to participate in the study.

By face-to-face interview questionnaires were completed by 1008 women after taking informed consent. Detailed questions in local language asked about knowledge of cancer cervix, knowledge of screening methods for cancer cervix, knowledge of availability of screening facility at various health centers, knowledge about risk factors for cancer cervix, knowledge about various symptoms of cancer cervix, knowledge about vaccination and its timing, willingness for pap smear to be taken. If woman is not willing than what was the reason. Not willing participant were than educated using pictorial charts about what is cancer cervix, how it develops, importance of pap smear, how it is to done, it will be painless and again willingness for pap smear was asked and outcome was recorded.

\section{Statistical analysis}

Data collected was analyzed using SPSS 18 and Med Cal software. Odds ratios were used to test the association between the binary variables (yes/no) and demographic characteristics. For all analyses, a p-value of less than 0.05 and a $95 \%$ confidence interval that does not span unity were considered as thresholds of statistical significance.

\section{RESULTS}

In this study total 1008 women participated (Table 1).

The age of women ranges from 21 years to 59 years, with a mean age of marriage $22.4 \pm 3.2$ years and mean age of first sexual intercourse is $21.8 \pm 2.9$. The majority (30.4\%) belong to age between $36-40$ years and majority (48.4\%) of participants belongs to 5000 to 10000 monthly income group. All (100\%) of them were married. Most (70.6\%) of them had received secondary education and $29.4 \%$ participant's attended higher secondary and above level of education. Higher screening rates were observed in older women i.e. $36-40$ years $(17.7 \%)$, women married after 27 years $(52.5 \%)$, more than higher secondary educated women $(18.4 \%)$, women in the highest income upper middle- and upper-income group (16.1\%), and women having more children's $(11.5 \%)$.

Study found that the knowledge of risk factors of cervical cancer among participants was $33.3 \%$ but most of them had incomplete knowledge (Table 2). $28.1 \%$ women were aware about time when cervical screening should be done. Regarding Pap smear 17.8\% women were aware, $26.5 \%$ women even knew about the method of Pap smear (Table 3). The awareness about availability of screening facility at health centre was found to be $19.6 \%$.

About vaccination $27.6 \%$ women replied positive which was credible that they know that it can be prevented though they did now when it can be given only $13.7 \%$ women knew correct timing of vaccination. Knowledge about HPV virus as causative agent for cancer cervix only $10.2 \%$ women gave affirmative response.

The highest knowledge on the risk factors was having multiple partner $(27.9 \%)$, whereas the lowest was the relationship between sexually transmitted infection and cervical cancer was only $(9.5 \%)$. 
Table 1: Distribution according to socio demographic characteristic.

\begin{tabular}{|c|c|c|c|c|c|}
\hline \multicolumn{6}{|c|}{ Sociodemographic characteristics of the participants n (\%) } \\
\hline \multicolumn{2}{|c|}{ Demographic characteristics } & $\mathrm{n}(\%)$ & Screened $(\%)$ & Unscreened $(\%$ & $\mathrm{Chi}^{2}$ \\
\hline \multirow[t]{5}{*}{ Age (years) } & $30-35$ & $269(26.7 \%)$ & $27(10.0 \%)$ & $242(90.0 \%)$ & \multirow{5}{*}{$\mathrm{Chi}^{2}: 3.2 \mathrm{p}$-value: 0.53} \\
\hline & $36-40$ & $307(30.4 \%)$ & $34(11.1 \%)$ & $273(88.9 \%)$ & \\
\hline & $41-45$ & $245(24.3 \%)$ & $29(11.8 \%)$ & $216(88.2 \%)$ & \\
\hline & $46-50$ & $125(12.4 \%)$ & $16(12.8 \%)$ & $109(87.2 \%)$ & \\
\hline & $51-55$ & $62(06.2 \%)$ & $11(17.7 \%)$ & $51(82.30 \%)$ & \\
\hline Married & Yes & $1008(100 \%)$ & $117(11.6 \%)$ & $891(88.4 \%)$ & \\
\hline \multirow{5}{*}{$\begin{array}{l}\text { Age at } \\
\text { marriage } \\
\text { (years) }\end{array}$} & $17-18$ & $63(6.2 \%)$ & $08(12.7 \%)$ & $55(87.3 \%)$ & \multirow{5}{*}{$\mathrm{Chi}^{2}: 69.03$ p-value: 0.0000} \\
\hline & $19-20$ & $226(22.4 \%)$ & $24(10.6 \%)$ & $202(89.4 \%)$ & \\
\hline & $21-24$ & $354(35.1 \%)$ & $36(10.2 \%)$ & $318(89.8 \%)$ & \\
\hline & $25-26$ & $325(32.4 \%)$ & $28(8.6 \%)$ & $297(91.4 \%)$ & \\
\hline & $>27$ & $40(3.9 \%)$ & $21(52.5 \%)$ & $19(47.5 \%)$ & \\
\hline \multirow{2}{*}{ Have children } & Yes & $890(88.2 \%)$ & $103(11.5 \%)$ & $787(88.5 \%)$ & \multirow[t]{2}{*}{ Chi $^{2}: 0.03$ p-value: 0.86} \\
\hline & No & $118(11.7 \%)$ & $13(11 \%)$ & $105(89 \%)$ & \\
\hline \multirow{5}{*}{$\begin{array}{l}\text { No of } \\
\text { children's }\end{array}$} & 0 & $122(12.1 \%)$ & $08(6.4 \%)$ & $114(93.6 \%)$ & \multirow{5}{*}{$\mathrm{Chi}^{2}: 26.8$ p-value: 0.00002} \\
\hline & 1 & $271(26.8 \%)$ & $24(8.9 \%)$ & $247(91.1 \%)$ & \\
\hline & 2 & $305(30.2 \%)$ & $37(12.1 \%)$ & $268(87.9 \%)$ & \\
\hline & 3 & $257(25.5 \%)$ & $31(12 \%)$ & $226(88 \%)$ & \\
\hline & $\geq 4$ & $53(2.3 \%)$ & $17(32.1 \%)$ & $36(67.9 \%)$ & \\
\hline \multirow[t]{2}{*}{ Education } & $\leq$ Secondary & $712(70.6 \%)$ & $62(8.7 \%)$ & $650(91.3 \%)$ & \multirow[b]{2}{*}{$\begin{array}{l}\mathrm{Chi}^{2}: 19.86 \text { p-value: } \\
<0.00001\end{array}$} \\
\hline & $\begin{array}{l}\geq \text { Higher } \\
\text { secondary or } \\
\text { above }\end{array}$ & $296(29.4 \%)$ & $55(18.4 \%)$ & $241(81.6 \%)$ & \\
\hline \multirow{4}{*}{$\begin{array}{l}\text { Income } \\
\text { grouping (per } \\
\text { month) }\end{array}$} & $<1000$ & $22(2.2 \%)$ & $01(4.5 \%)$ & $21(95.5 \%)$ & \multirow{4}{*}{ Chi $^{2}: 13.49$ p-value: 0.003} \\
\hline & $1000-5000$ & $118(11.8 \%)$ & $08(6.8 \%)$ & $110(93.2 \%)$ & \\
\hline & $5000-10000$ & $488(48.4 \%)$ & $46(8.6 \%)$ & $441(91.8 \%)$ & \\
\hline & $\geq 10000$ & $380(37.6 \%)$ & $61(16.1 \%)$ & $319(83.9 \%)$ & \\
\hline \multicolumn{2}{|c|}{ Age at marriage $($ mean $\pm S D)$} & $22.4 \pm 3.2$ & & & \\
\hline \multicolumn{2}{|c|}{$\begin{array}{l}\text { Age at } 1^{\text {st }} \text { sexual intercourse } \\
(\text { mean } \pm S D)\end{array}$} & $21.8 \pm 2.9$ & & & \\
\hline
\end{tabular}

Table 2: Distribution according to knowledge of risk factors of cancer cervix.

\begin{tabular}{|lll|}
\hline Knowledge regarding risk factors of cervical cancer & Number responded yes & $(\%)$ \\
\hline Questions related to knowledge & 282 & $27.9 \%$ \\
\hline Knowledge about cervical cancer due to multiple partners & 178 & $17.6 \%$ \\
\hline Knowledge about cervical cancer due to more children's & 112 & $11.1 \%$ \\
\hline Knowledge about cervical cancer due early sexual activity & 118 & $11.7 \%$ \\
\hline Knowledge about cervical cancer with early marriage & 96 & $9.5 \%$ \\
\hline
\end{tabular}

The highest knowledge on the symptoms of cervical cancer was presentation with foul smelling or blood mixed vaginal discharge $(25.6 \%)$, whereas the lowest $(14.5 \%)$ was the relationship between burning micturition and cervical cancer (Table 4).

Analysis of determinants of uptake of cervical cancer screening this study showed that younger women (30-35 years) and those with early marriage were less likely to be screened [OR $1.24(0.78,1.32) \mathrm{p}$ value 0.05$]$ and [OR $1.12(0.34,2.65) \mathrm{p}$ value 0.08 respectively compared to women, who have children, were more educated and belongs to higher income group were more likely to be screened [OR $2.43(0.98,2.78) \mathrm{p}$ value 0.000$]$, [OR 2.32 $(1.21,2.89) \mathrm{p}$ value 0.001$]$, and [OR $2.61(0.98,2.38) \mathrm{p}$ value 0.000] respectively (Table 5). Among 1008 women recruited after counselling $730(72.4 \%)$ gave consent for screening whereas $278(27.6 \%)$ refused pap smear. The most common reason behind refusal for cervical cancer screening among participant's was that the Pap smear test will make them worry $(91.4 \%)$, followed by anxiety and fear $(84.2 \%) .24 .1 \%$ women stated that there was no encouragement and consent from the partner (Table 6). 
Table 3: Participants knowledge regarding symptoms of cervical cancer.

Knowledge regarding symptoms of cervical cancer

Questions related to knowledge

Knowledge about cervical cancer may present with postcoital bleeding

Number responded yes

$(\%)$

Knowledge about cervical cancer may present with foul smelling or vaginal discharge with blood

254

Knowledge about cervical cancer may present with postmenopausal bleeding

258

$25.6 \%$

Knowledge about cervical cancer may present with lower abdominal pain

Knowledge about cervical cancer may present with dysmenorrhoea

198

$19.6 \%$

Knowledge about cervical cancer may present with urinary retention

179

$17.8 \%$

216

$17.9 \%$

Knowledge about cervical cancer may present with burning micturition

162

$16.1 \%$

146

$14.5 \%$

Table 4: Participants knowledge regarding investigations, vaccination and spread of cervical cancer.

Knowledge regarding investigations, vaccination and spread of cervical cancer

Questions related to knowledge Number responded yes

$(\%)$

Heard about investigation of pap smear or another cervical cancer screening

Awareness of pap smear

336

$33.3 \%$

Awareness for time of investigation for cervical screening

179

$17.8 \%$

Awareness for method of pap smear

283

$28.1 \%$

Awareness for cervical screening health centre

267

$26.5 \%$

Awareness of virus causing cervical cancer

198

$19.6 \%$

Awareness of vaccination for cervical cancer

103

$10.2 \%$

Awareness of age for vaccination of cervical cancer

278

$27.6 \%$

138

$13.7 \%$

Table 5: Determinants of uptake of cervical cancer screening.

\begin{tabular}{|c|c|c|c|}
\hline \multicolumn{2}{|c|}{ Demographic characteristics } & Odds ratio (95\% CI) & p value \\
\hline \multirow{5}{*}{ Age (years) } & $30-35$ & $1.24(0.78-1.32)$ & 0.05 \\
\hline & $36-40$ & $1.89(1.59-4.98)$ & 0.001 \\
\hline & $41-45$ & $3.10(0.89-1.67)$ & 0.000 \\
\hline & $46-50$ & $3.67(1.98-3.45)$ & 0.000 \\
\hline & $51-55$ & $4.76(2.79-4.86)$ & 0.000 \\
\hline \multirow{3}{*}{ Age at marriage (years) } & $19-20$ & $1.12(0.34-2.65)$ & 0.08 \\
\hline & $21-24$ & $1.34(0.56-3.12)$ & 0.02 \\
\hline & $25-26$ & $2.21(0.78-2.18)$ & 0.000 \\
\hline \multirow{2}{*}{ Have children } & Yes & $2.43(0.98-2.78)$ & 0.000 \\
\hline & No & 1 & \\
\hline \multirow{2}{*}{ Education } & $\leq$ Secondary & $1.64(0.85-2.18)$ & 0.000 \\
\hline & $\geq$ Higher secondary or above & $2.32(1.21-2.89)$ & 0.001 \\
\hline \multirow{2}{*}{$\begin{array}{l}\text { Income grouping (per } \\
\text { month) }\end{array}$} & $1000-5000$ & $1.74(0.76-2.12)$ & 0.01 \\
\hline & $5000-10000$ & $2.61(0.98-2.38)$ & 0.000 \\
\hline
\end{tabular}

Table 6: Distribution according to reasons for not giving consent for cervical cancer screening.

Reasons

Pap smear test will make them worry

$\mathrm{N}(\%)$

Anxiety and fear

$254(91.4 \%)$

Concerning intimacy associated with the examination

$234(84.2 \%)$

Lack of information about screening sites

$191(68.7 \%)$

No consent from husband/father

$82(29.5 \%)$

Pain and discomfort

$67(24.1 \%)$

Embarrassment

$65(23.4 \%)$

$58(20.9 \%)$ 


\section{DISCUSSION}

In northern Indian study they have found that $98.5 \%$ were unaware of any form of screening method for cancer cervix whereas Narayana $\mathrm{G}$ et al reported $74.6 \%$ awareness which is very high compared to this study. So, though women of Chhattisgarh are not highly educated they are well aware (33.3\%).

This study showed that influence of knowledge among participant's i.e. knowledge about cervical cancer is more among educated participant's (18.4\%) and more readily accepted as compared with low educated participant's $(8.7 \%)$

\section{Factors affecting awareness}

Regarding the barriers of cervical cancer screening the most common reason observed was that Pap smear test will make them worry "and the "fear of discovery of cancer" is one of the most common barriers among study participants.

This setting counsel and recommend for Pap smear to every eligible woman who present in study outdoor patient department and in this study $72 \%$ women agreed for screening.

In 2015, $16.4 \%$ of eligible Kenyan women had been screened for cervical cancer, a marginally higher figure than the $14 \%$ shown in the 2014 KDHS. ${ }^{6}$ Awareness of cervical cancer screening was high with $67.9 \%$ of un screened women being aware, a lower level than in the KDHS where it was $76 \%$. In a study done in Uganda, only $4.8 \%$ of women had undergone screening for cervical cancer despite high levels of knowledge about cervical cancer and its risk factors. ${ }^{7}$

In this study higher screening rates were seen in older, more educated, affluent women and those living in urban areas. This is similar to a study done in Tanzania. ${ }^{8} \mathrm{~A}$ study in France found high screening rates among younger women aged 25-35 year. ${ }^{9}$

Embarrassment was reported as barriers on $20.9 \%$ participants. In addition, the possibility of pain needs to be acknowledged rather than ignored so that women can feel a sense of trust. ${ }^{10}$

In this study there is a relationship between income, knowledge and age at marriage. Similar findings were reported in many Indian studies i.e., in 2014 Siddharthar JR studied and found that less than half of the study population $(178,44.5 \%)$ knew about cervical cancer. Less than one-fourth of the population knew about screening services for prevention of cervical cancer, and majority $(389,97.2 \%)$ were not aware of vaccination as prevention for cervical cancer. and concluded in their study that poor knowledge about cervical cancer and is unaware of the concept of prevention. Hence extensive health education to the public is needed regarding cervical cancer and its prevention. ${ }^{11}$ In 2017 the study done by Cecilia et al in Malaysia found that the response rate was $98.2 \%$ and concluded that marital status, knowledge, and having a regular health care provider were the predictive factors. ${ }^{12}$ Another study in 2017 by Singh $S$ et al in north India, concluded that recognition of cervical cancer risk factors and symptoms was low and targeted interventions including increasing availability of HPV vaccination, population-based cervical screening and diagnostic services can translate high awareness into actual benefits. ${ }^{13}$

Another study in 2017 by Narayana $G$ et al found that most of $(301 ; 74.6 \%)$ the respondents had heard about cervical cancer and majority of them are heard from media $(168 ; 41.6 \%)$ and friends $(83 ; 20.5 \%)$ and concluded that Although women are having good knowledge, positive attitude toward cervical cancer screening and prevention still there is a gap to transform it into practice. There is a need for more educational programs to connect identified knowledge slits and uplift of regular practice of cervical cancer screening. ${ }^{14}$

However, we believe the strengths of this study include the fact that we were able to access a population that has not been widely studied, and that this is one of the first studies describing knowledge and beliefs about cervical cancer in this population and reveals potential targets for interventions to improve cervical cancer screening rates.

\section{CONCLUSION}

This study discovered several important factors relating to cultural, religious and sexual behaviour that shaped educated and uneducated Indian woman's perspectives on Cervical cancer screening. Study came to conclusion that cervical cancer considered a 'silent disease' could be detected with early screening only by addressing woman's fear, pain and embarrassment, along with social education overcoming cultural influence that deterred them from undergoing screening.

\section{ACKNOWLEDGMENTS}

The authors were thankful to all the faculty and technical staff of department of obstetrics and gynecology, Dr. BRAM Hospital, Pt. JNM Medical College, Raipur, Chhattisgarh India, for their cooperation and support during the entire study period. Authors acknowledge the immense help received from the scholars whose articles are cited and included in references of this manuscript. The authors are also grateful to authors/editors/publishers of all those articles, journals and books from where the literature for this article has been reviewed and discussed.

Funding: No funding sources Conflict of interest: None declared

Ethical approval: The study was approved by the Institutional Ethics Committee 


\section{REFERENCES}

1. WHO. INT, 2019. Available at: http://www.who.int/healthtopics/cancer\#tab=tab1. Accessed on $12^{\text {th }}$ August 2019.

2. WHO. INT, $2018 . \quad$ Available at: https://www.who.int/cancer/world-cancerday/2018/en/. Accessed on $12^{\text {th }}$ August 2019.

3. Centre for disease control and prevention, 2019. Available at: https://www.cdc.gov/cancer/vagvulv/pdf/vagvulv_fa cts.pdf. Accessed on $18^{\text {th }}$ August 2019.

4. WHO. INT, 2019. Available at: https://www.who.int/news-room/factsheets/detail/human-papillomavirus-(hpv)-andcervical-cancer. Accessed on $18^{\text {th }}$ August 2019.

5. WHO handbook for guideline development. Geneva, World Health Organization; WHO guidelines for screening and treatment of precancerous lesions for cervical cancer; 2013.

6. Kenya national bureau of statistics, ministry of health, national aids control council, Kenya medical research institute, national council for population and development, the DHS program ICF international. Kenya demographic and health survey 2014. 2015. Available at: https://dhsprogram.com/pubs/pdf/FR308/FR308.pdf. Accessed on $12^{\text {th }}$ August 2019.

7. Ndejjo R, Mukama T, Musabyimana A, Musoke D, Bonell C, Yeates K, et al. Uptake of cervical cancer screening and associated factors among women in rural Uganda: a cross sectional study. PLoS One. 2016;11:2.

8. Perng P, Perng W, Ngoma T, Kahesa C, Mwaiselage $\mathrm{J}$, Merajver SD, et al. Promoters of and barriers to cervical cancer screening in a rural setting in Tanzania. Int J Gynaecol Obstet. 2013;123(3):221-5.
9. Sicsic J, Franc C. Obstacles to the uptake of breast, cervical, and colorectal cancer screenings: what remains to be achieved by French national programmes? BMC Health Serv Res. 2014;14(1):465.

10. Abotchie PN, Shokar NN. Cervical cancer screening among college students in Ghana: knowledge and health beliefs. Int J Gynecol Cancer. 2009;19(3):4126.

11. Siddharthar JR, Rajkumar B, Deivasigamani K. Knowledge, awareness and prevention of cervical cancer among women attending a tertiary care hospital in Puducherry, India. J Clin Diagn Res. 2014;8(6):OC01-OC03.

12. Nwabichie CC, Manaf RA, Ismail SB. Factors affecting uptake of cervical cancer screening among African women in Klang Valley, Malaysia. Asian Pac J Cancer Prev. 2018;19(3):825-31.

13. Singh S, Narayan N, Sinha R, Sinha P, Sinha VP, Upadhye JJ. Awareness about cervical cancer risk factors and symptoms. Int J Reprod Contracept Obstet Gynecol. 2018;7:4987-91.

14. Narayana G, Suchitra MJ, Sunanda G, Ramaiah JD, Kumar BP, Veerabhadrappa KV. Knowledge, attitude, and practice toward cervical cancer among women attending obstetrics and gynecology department: a cross-sectional, hospital-based survey in South India. Indian J Cancer. 2017;54(2):481.

Cite this article as: Lal NS, Kujur A, Tiwari P. Study of assessment of awareness for screening of cervical cancer in women attending gynecology outdoor patient department. Int J Reprod Contracept Obstet Gynecol 2020;9:1800-5. 